\title{
Reconstitution of thymic function in HIV-1 patients treated with highly active antiretroviral therapy
}

\author{
Ping Ye, ${ }^{\mathrm{a}}$ Athena P. Kourtis, ${ }^{\mathrm{b}}$ and Denise E. Kirschner ${ }^{\mathrm{a}, *}$ \\ ${ }^{a}$ Department of Microbiology and Immunology, University of Michigan Medical School, Ann Arbor, MI 48109, USA \\ ${ }^{\mathrm{b}}$ Eastern Virginia Medical School, CONRAD/MS-K34, HIV Section/Division of Reproductive Health, National Center for Chronic Disease Prevention \\ and Health Promotion, Centers for Disease Control and Prevention, Atlanta, GA 30341, USA
}

Received 13 August 2002; accepted with revision 28 October 2002

\begin{abstract}
The extent to which highly active antiretroviral therapy can restore thymic function in HIV-1 infected patients is not known. We simulate treatment using a temporal model of thymopoiesis during HIV-1 infection, tracking thymic function by the number of recent thymic emigrants (RTE) exported to the periphery per day. Our results suggest that suppressing viral load in peripheral blood and improving inherent thymic function are necessary for the reconstitution of RTE levels in adult thymic infection with either R5 or X4 HIV-1 strains. This is also the case in pediatric thymic infection with R5 strains. However, recovery of RTE levels during pediatric infection with X4 strains also depends on high drug efficacy within the thymus. We further predict that protease inhibitors have high levels of efficacy directly suppressing viral replication within the thymus, while reverse transcriptase inhibitors have low efficacy.
\end{abstract}

(C) 2003 Elsevier Science (USA). All rights reserved.

Keywords: Thymus; HAART; Immune reconstitution; Pediatric infection; Mathematical model

\section{Introduction}

HIV-1 infection induces a progressive decline of peripheral $\mathrm{CD}^{+}{ }^{+} \mathrm{T}$ cells which leads to immunodeficiency and opportunistic infections. Highly active antiretroviral therapy (HAART) with combinations of viral protease and reverse transcriptase inhibitors is the most widely used treatment strategy for HIV-1 infection. Evidence accumulated in the past decade has proven that HAART is remarkably successful at suppressing viral load [1]. However, most HIV-1infected patients only achieve partial immune system recovery during HAART. This partial reconstitution is represented by a proliferative response to only some recall antigens [1].

The thymus provides new naive $\mathrm{T}$ cells to the periphery that are capable of responding to both recall and new antigens. This response is necessary for immune recovery in HIV-1-infected patients. Therefore, thymic function recon-

\footnotetext{
* Corresponding author. Fax: +1-734-647-7723.

E-mail address: kirschne@umich.edu (D.E. Kirschner).
}

stitution is critical. During HAART, naive T cells have been observed to increase [2-5], which may be due to an increased number of recent thymic emigrants (RTE) exported from the thymus. T cell receptor excision circles (TREC), which are generated during $\mathrm{T}$ cell receptor gene rearrangements within the thymus, have recently been used to represent RTE levels [6]. Several clinical studies demonstrate recovery of TREC concentrations to normal levels in some patients during HAART $[2,6,7]$. Increased thymic volume has been observed in some HIV-1-infected patients during treatment $[5,8,9]$. Recent data suggest that thymic enlargement in adults represents active thymopoiesis [10]. Larger thymic size with elevated $\mathrm{CD} 4^{+} \mathrm{T}$ cell counts and TREC levels were also observed together after HAART was initiated, implying a pivotal role of the thymus in immune reconstitution [5,11]. Children have both earlier and greater increases in naive $\mathrm{T}$ cells and TREC concentrations than adults $[2,4,7]$, suggesting that the thymus is more active in children and therefore has a higher potential for immune reconstitution. These data imply that recovery of thymic function could occur in HIV-1-infected patients on 
Table 1

$\mathrm{T}$ lymphocyte counts in the first year of life in HIV-1-infected $\mathrm{TD}^{+}$and $\mathrm{TD}^{-}$patients

\begin{tabular}{|c|c|c|c|c|c|}
\hline \multirow{2}{*}{$\begin{array}{l}\text { Patient } \\
1\end{array}$} & \multirow{2}{*}{$\begin{array}{l}\text { TD status } \\
\mathrm{TD}^{+\mathrm{a}}\end{array}$} & \multirow{2}{*}{$\begin{array}{l}\text { Therapy } \\
\text { RTI }^{\mathrm{c}}\end{array}$} & \multirow{2}{*}{$\begin{array}{l}\text { Age therapy initiated (months) } \\
5\end{array}$} & \multicolumn{2}{|c|}{$\begin{array}{l}\text { CD } 4 / C D 8 \text { cells per } \mathrm{mm}^{3} \text { blood (at age in } \\
\text { months) }\end{array}$} \\
\hline & & & & $\begin{array}{l}883 / 1138(5) \\
104 / 188(11)\end{array}$ & $300 / 392(6)$ \\
\hline 2 & $\mathrm{TD}^{+}$ & RTI & 6 & $320 / 239(7)$ & $134 / 133(10)$ \\
\hline 3 & $\mathrm{TD}^{+}$ & RTI & 5 & $500 / 530(4)$ & $383 / 100(9)$ \\
\hline 4 & $\mathrm{TD}^{+}$ & RTI & 5 & $990 / 475$ (4) & $1014 / 364(8)$ \\
\hline \multirow[t]{3}{*}{5} & $\mathrm{TD}^{+}$ & HAART & 3 & $173 / 196(3)$ & $676 / \mathrm{ND}^{\mathrm{d}}(4)$ \\
\hline & & & & $991 / 710(6)$ & $1106 / 492(8)$ \\
\hline & & & & $1759 / 848(9)$ & $1280 / 333(12)$ \\
\hline 6 & $\mathrm{TD}^{-\mathrm{b}}$ & RTI & 3 & $1285 / 1771(4)$ & $752 / 2424(10)$ \\
\hline 7 & $\mathrm{TD}^{-}$ & RTI & 5 & $2540 / 3978(5)$ & $1306 / 3003(13)$ \\
\hline 8 & $\mathrm{TD}^{-}$ & RTI & 5 & $2360 / 998$ (4) & $2551 / 1782(10)$ \\
\hline 9 & $\mathrm{TD}^{-}$ & RTI & 5 & $3312 / 1448(6)$ & $2501 / 4026(10)$ \\
\hline 10 & $\mathrm{TD}^{-}$ & RTI & 6 & $1033 / 488(7)$ & $2111 / 1266(9)$ \\
\hline 11 & $\mathrm{TD}^{-}$ & RTI & 4 & $792 / 939$ (6) & $1071 / 1159(9)$ \\
\hline 12 & $\mathrm{TD}^{-}$ & RTI & 6 & $1739 / 2086(6)$ & $1345 / 2383(10)$ \\
\hline \multirow[t]{4}{*}{$13^{\mathrm{e}}$} & $\mathrm{TD}^{-}$ & HAART & 4.6 & $3580 / 1310(4.6)$ & $3190 / 1080(5)$ \\
\hline & & & & $2630 / 730(5.5)$ & $2740 / 800(6.5)$ \\
\hline & & & & $3558 / 1120(7.5)$ & $4380 / 1240(10.5)$ \\
\hline & & & & $3536 / 1086(13.5)$ & \\
\hline \multirow[t]{3}{*}{$14^{\mathrm{e}}$} & $\mathrm{TD}^{-}$ & HAART & 4.9 & $752 / 1333(4.9)$ & $1934 / 2134(5.4)$ \\
\hline & & & & $2004 / 2790(5.8)$ & $1942 / 1884(6.8)$ \\
\hline & & & & $2882 / 2074(7.8)$ & $2692 / 1692(10.8)$ \\
\hline
\end{tabular}

${ }^{\mathrm{a}} \mathrm{TD}^{+}$, with thymic dysfunction profile.

${ }^{\mathrm{b}} \mathrm{TD}^{-}$, without thymic dysfunction profile.

${ }^{\mathrm{c}}$ RTI, nucleoside analogues of reverse transcriptase inhibitors.

${ }^{\mathrm{d}} \mathrm{ND}$, no data.

${ }^{\mathrm{e}}$ Unpublished data from Dr. van Rossum and [23].

HAART. However, specific mechanisms that contribute to this recovery are not known.

The presence of HIV-1-infected cells in various tissue compartments, including the thymus, central nerve system, and testes, may be due to low accessibility of drugs to those sites. These anatomical HIV-1 reservoirs have blood-organ barriers where HIV-1 replication is protected from drugs $[12,13]$. No data have been reported describing the ability of HAART agents to cross the blood-thymus barrier and penetrate into the thymus. However, patients with thymic carcinoma have been observed to achieve positive responses with systemic chemotherapy, suggesting that certain drugs have consistent efficacy within the thymus [14]. Several studies have also detected the penetration of nucleoside reverse transcriptase inhibitors into cerebrospinal fluid (CSF), including lamivudine, stavudine, and zidovudine [15-17]. Concentrations within CSF were consistent over time, unlike those within blood [15]. Lamivudine concentrations in both serum and CSF increase proportionally with dosage [17]. Penetration of protease inhibitors, such as indinavir, ritonavir, and saquinavir, into CSF and testes has also been observed $[18,19]$. Drug penetration improves the potency of the regimen in these anatomical HIV reservoirs. We hypothesize that, similarly, the ability of antiretroviral drugs to enter the thymus is a critical issue in the treatment of thymic HIV-1 infection.

We have developed a mathematical model describing human thymopoiesis during both health and HIV-1 infection in pediatric and adult patients [20,21]. Applying this model, we explore mechanisms that contribute to thymic function reconstitution during HAART. This study will help to identify treatment strategies that induce an increase in the number of RTE produced per day through restoration of thymic function.

\section{Materials and methods}

\section{Patient studies}

We present data from 14 HIV-infected infants who were infected through perinatal transmission and who were treated with antiretroviral agents in the first 6 months of life (Table 1). Five of these had a peripheral blood immunophenotypic profile consistent with thymic dysfunction $\left(\mathrm{TD}^{+}\right)$, which includes very early and profound $\mathrm{CD} 4^{+}$and $\mathrm{CD} 8^{+} \mathrm{T}$ lymphocyte decreases, as previously described [22]. Since current treatment recommendations for HIV-infected infants dictate combination regimens as soon as $\mathrm{HIV}^{+}$status 


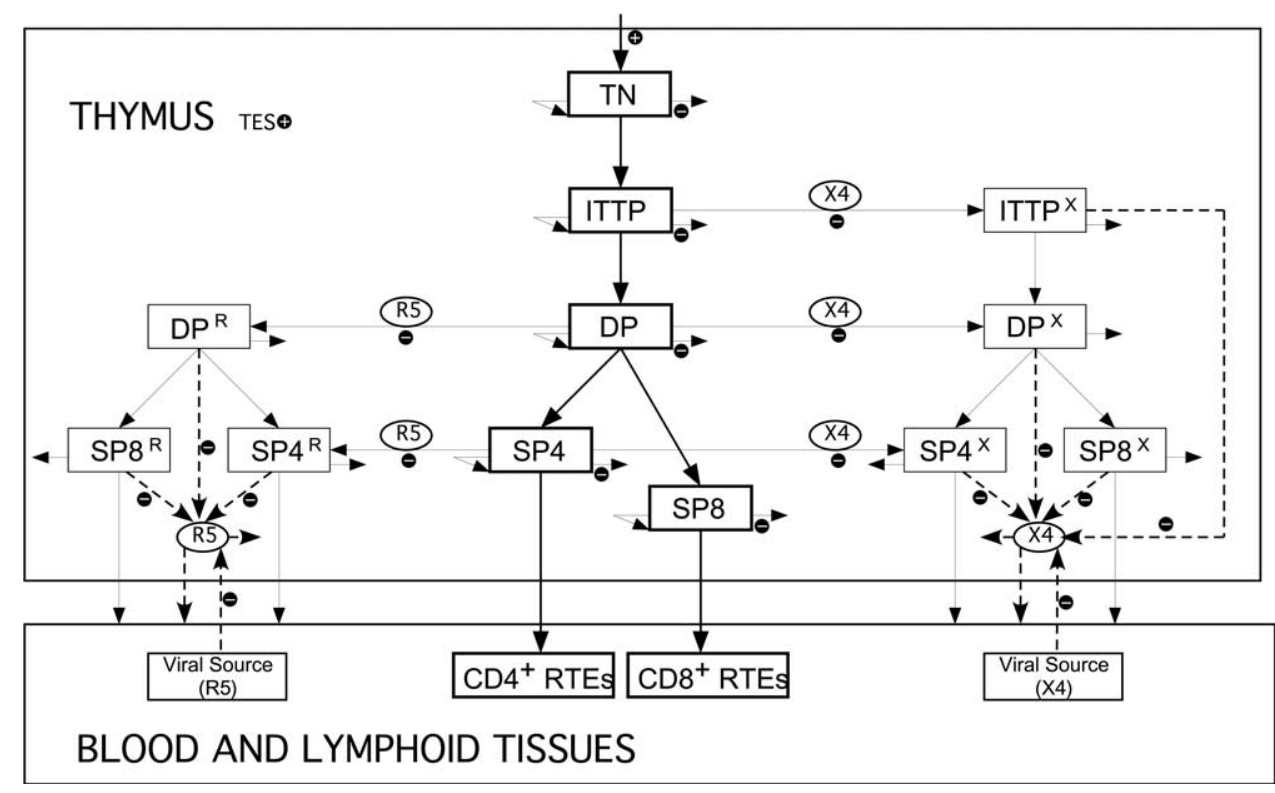

Fig. 1. The model of thymic function reconstitution during HAART. Rectangles represent cell populations and ellipses represent viral populations. Cell dynamics are illustrated using solid lines and viral dynamics are illustrated using dashed lines. Five uninfected thymocyte subsets are TN, ITTP, DP, SP4, and SP8 cells. SP4 and SP8 cells emigrate to the periphery as RTE [20]. R5 or X4 strains flow in from the blood into the thymus and infect thymocyte subsets. Infected thymocytes further differentiate and generate new virions [21]. The effects of HAART are represented by plus or minus signs on cell and viral dynamics. Plus signs suggest an increase while minus signs suggest a decrease. HAART decreases viral influx from the blood into the thymus, increases the source of stem cells from bone marrow into the thymus, increases the maximal cell numbers in the thymic epithelial space (TES), and decreases the enhanced death of uninfected thymocytes. If HAART drugs can penetrate into the thymus, thymic drug efficacy is represented by a decrease in viral infection and production rates. Model equations and parameter values representing treatment effects are illustrated in the Appendix.

is diagnosed (usually within the first 3 months of life), identification of $\mathrm{TD}^{+}$infants has been limited to only those cases where maternal $\mathrm{HIV}^{+}$status is unknown at the time of birth. Therefore, most of the data used in this study are from the pre-HAART era, when therapy was based on nucleoside reverse transcriptase inhibitors, and was initiated based on clinical or laboratory indications of disease progression. Four of the $5 \mathrm{TD}^{+}$patients were initiated on antiretroviral therapy with zidovudine or zidovudine/didanosine between 5 and 6 months of age due to a marked $\mathrm{CD}^{+} \mathrm{T}$ lymphocyte decline (patients 1-4). The 5th patient was initiated on a zidovudine/lamivudine/ritonavir combination regimen soon after initial presentation with Pneumocystis carinii pneumonia at 3 months of age (patient 5). Nine HIV-infected infants without thymic dysfunction profile $\left(\mathrm{TD}^{-}\right)$, who concurrently started therapy between 5 and 6 months of age, were also selected for comparison. Seven of the $9 \mathrm{TD}^{-}$patients were treated with nucleoside analogue reverse transcriptase inhibitors (patients 6-12), and 2 were on HAART (patients 13 and 14; unpublished data generously donated by Dr. van Rossum) [23].

\section{Mathematical models}

We developed mathematical models illustrating human thymopoiesis and thymic HIV-1 infection [20,21]. We now apply these models to investigate thymic function recovery during HAART in HIV-1 patients. The previous models and current treatment methods are detailed below.

\section{Thymopoiesis model}

We previously developed a mathematical model illustrating human thymopoiesis over an 80-year lifespan [20]. Hemopoietic progenitor cells from bone marrow migrate into the thymus and differentiate into triple negative (TN) cells. TN cells then differentiate into intrathymic $\mathrm{T}$ progenitor (ITTP) cells, double positive (DP) cells, and either $\mathrm{CD}^{+}{ }^{+}$single positive (SP4) or $\mathrm{CD} 8^{+}$single positive (SP8) cells sequentially. A subset of SP4 and SP8 cells migrate into the periphery to become $\mathrm{CD} 4^{+}$or $\mathrm{CD} 8^{+} \mathrm{RTE}$ (Fig. 1). This model quantifies the number of RTE exported per day from the thymus over 80 years, which cannot be experimentally measured at present [20].

\section{Thymic infection model}

Building on the thymopoiesis model described above, we then studied human thymic infection with different HIV-1 strains in pediatric and adult patients, respectively [21]. HIV-1 isolates that use CCR5 as a coreceptor are termed R5 strains, while isolates using CXCR4 as a coreceptor are designated X4 strains [24]. Either R5 or X4 strains may influx from the periphery into the thymus. R5 strains infect 
DP and SP4 cells while X4 strains infect ITTP, DP, and SP4 cells [21]. Infected subsets can further differentiate into next-stage thymocytes. New virions are generated by infected thymocytes and emigrate to the periphery (Fig. 1). Thymic infection also accelerates the death rate of uninfected thymocytes and involution of the thymic epithelial space (TES), which is the functional thymic tissue containing all thymocytes. The level of hemopoietic progenitor cells decreases due to bone marrow HIV-1 infection [21]. Our model results suggested that thymic infection with different HIV-1 strains induces thymic dysfunction to varying degrees, contributing to differences in disease progression as is observed in both HIV-1-infected children and adults. This model also suggests that thymic infection in children is more severe than in adults, particularly during $\mathrm{X} 4$ infection. This outcome is likely due to both a higher viral load and a more active thymus in pediatric patients [21].

\section{Thymic treatment model}

We now apply the thymic infection model [21] to study mechanisms related to thymic function reconstitution during HAART. Model equations and parameter values representing treatment effects are detailed in the Appendix.

Drug-naive patients who are virological responders to HAART achieve undetectable levels of plasma HIV-1 RNA within 3 months of therapy in an exponential manner ( $\leq 100$ copies RNA/ml) [3,8]. To simulate the reduction of blood viral load during HAART, the rate of viral influx into the thymus is decreased to a low, constant level after initiating treatment for 3 months (Fig. 1, minus signs). We suppress the rate of viral influx from blood into the thymus to the same levels for pediatric and adult patients.

TREC concentrations within $\mathrm{CD} 4^{+}$and $\mathrm{CD} 8^{+}$naive $\mathrm{T}$ cells were observed to have a sustained rise for up to 1 year after initiation of HAART together with the suppression of viral load $[2,6,7,25]$. This indicates that recovery of thymic function lasts for an extended time after blood viral load is initially suppressed. Other factors may also aid thymic function recovery during HAART. Increased numbers of hemopoietic progenitor cells from the bone marrow were observed after initiation of HAART, which may increase the stem cell source into the thymus $[26,27]$. To reproduce this effect, the term representing the source of stem cells is augmented (Fig. 1, plus sign). An increased volume of thymic tissue was detected in patients after HAART was initiated $[5,8,9]$. Both phenotype and function of thymocytes return to normal following antiretroviral treatment in SCID-hu mice $[28,29]$. The recovery of stromal cell function and normalization of the cytokine network may account for this restoration in thymic function. Thus, we increase the maximal cell numbers in the TES region (Fig. 1, plus sign) and decrease the enhanced death of uninfected thymocytes during HAART (Fig. 1, minus signs).

We simulate drug efficacy within the thymus by reducing viral infection and production rates (Fig. 1, minus signs). We vary drug efficacy from 0 to $100 \%$, depending on the assumption of drug penetration into the thymus.

\section{Results}

\section{Impact of HAART on pediatric thymic function}

Vertical HIV-1 infection typically occurs during delivery or in late-stage pregnancy [30]; therefore, we simulate infection occurring at birth. Currently, infected infants are initiated on HAART very early in life. Similarly, in our virtual pediatric thymus model, HAART is initiated 3 months after birth. As drug efficacy within the thymus is not known, we simulate a range of thymic drug efficacies $(0$ and $100 \%$ ) for comparison of total uninfected thymocytes and SP4/SP8 ratios, respectively (Fig. 2). In healthy individuals (no treatment), total thymocytes increase to their maximal value from birth to age 1 and then gradually decrease; the SP4/SP8 ratio remains a constant of 2 (Fig. 2, solid lines). When either R5- or X4-infected individuals are initiated on HAART in the virtual model, rapid rises in total thymocytes and SP4/SP8 ratio are predicted in both $0 \%$ thymic drug efficacy (Figs. 2A and 2B, dotted and dashed lines) and $100 \%$ thymic drug efficacy (Figs. 2C and 2D, dotted and dashed lines). This stems both from suppression of blood viral influx and from recovery of inherent thymic function. Decreasing the rate of viral influx benefits all thymocyte subsets, since it directly reduces intrathymic viral load, reducing the number of infected cells. Thus, our model suggests that control of peripheral HIV-1 loads during treatment is a key determinant in restoring thymocytes. The continuing increase in total thymocytes and SP4/SP8 ratio is further due to an increase in stem cell source, an increase in the number of thymocytes in the TES region, and a decrease in enhanced death of uninfected thymocytes. This suggests the need for a treatment strategy aimed at improving inherent thymic function, such as recovering stromal cell function, normalizing the cytokine network, or controlling inflammation. These approaches should be considered together with suppression of peripheral viral replication to achieve maximal restoration of thymic function.

Even without thymic drug efficacy, our virtual studies indicate that pediatric patients infected with R5 strains should respond well to HAART. Total thymocytes and the SP4/SP8 ratio rebound to almost normal (Figs. 2A and 2B, dotted lines); intrathymic R5 viral load and R5-infected thymocytes are suppressed to very low levels (simulation data on HAART not shown). However, simulated individuals infected with the more virulent $\mathrm{X} 4$ strains respond poorly to HAART if there is no thymic drug efficacy. Total thymocytes recover to less than $30 \%$ compared with healthy individuals and the SP4/SP8 ratio does not return to normal (Figs. 2A and 2B, dashed lines); intrathymic X4 viral load and $\mathrm{X} 4$-infected thymocytes rise to high levels due to the 

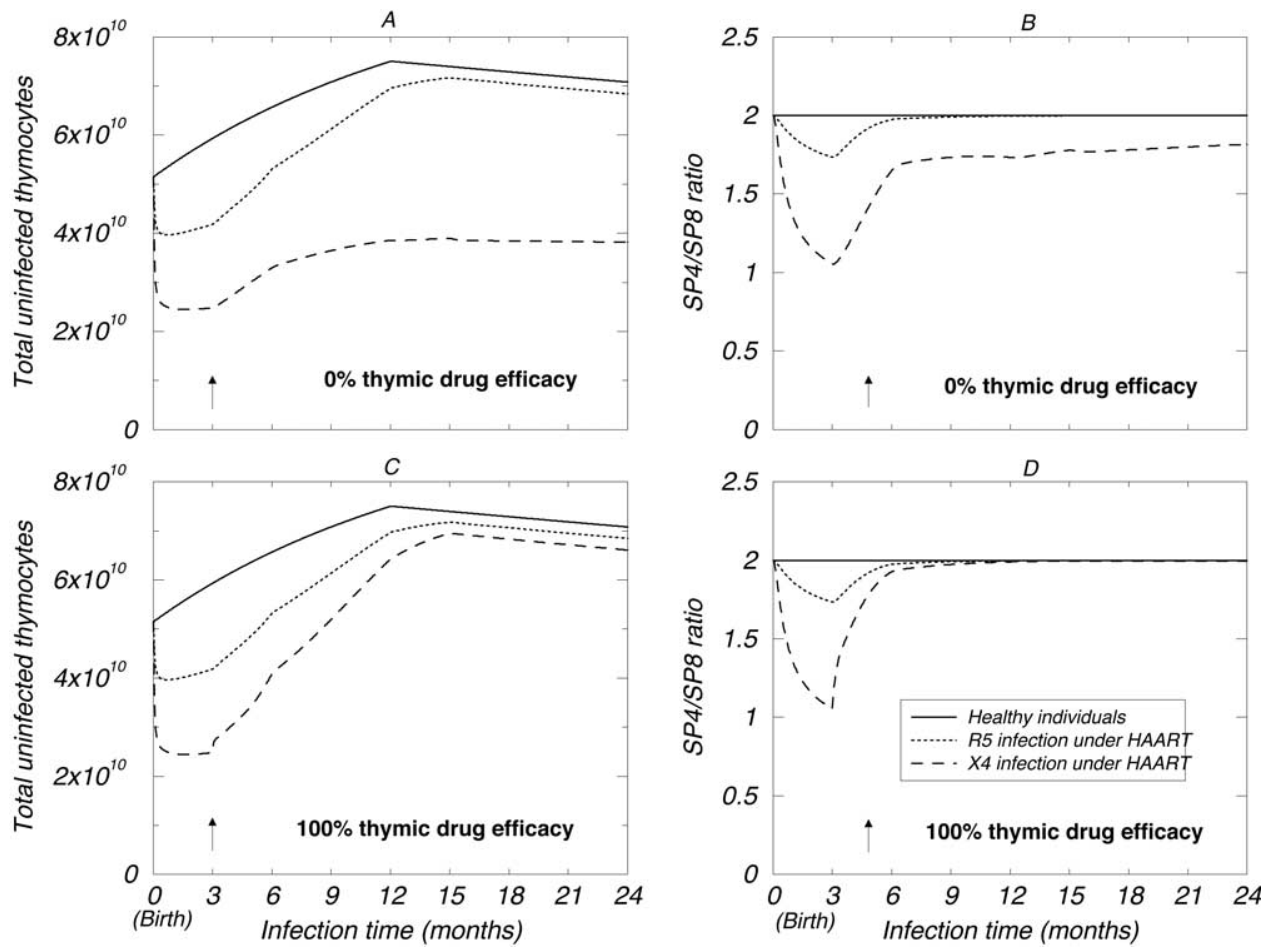

Fig. 2. Virtual pediatric infection: simulations of thymocyte dynamics during HAART. Three scenarios are presented: healthy controls and R5 or X4 infection during HAART. HIV-1 infection occurs at birth. The arrow points to the time when HAART is initiated during R5 or X4 infection. A represents total uninfected thymocytes if HAART has 0\% thymic efficacy. B represents SP4/SP8 ratio if HAART has 0\% thymic efficacy. C represents total uninfected thymocytes if HAART has 100\% thymic efficacy. D represents SP4/SP8 ratio if HAART has $100 \%$ thymic efficacy.

availability of more target cells for X4 strains (simulation data on HAART not shown). In contrast, if drugs achieve $100 \%$ efficacy within the thymus, total thymocytes and SP4/SP8 ratio return to almost normal levels during either R5 or X4 infection (Figs. 2C and 2D, dotted and dashed lines). This effect is achieved by direct control of viral replication within the thymus. With $100 \%$ thymic drug efficacy, intrathymic viral load and infected thymocytes are suppressed to very low levels for either R5 or X4 infection (simulation data on HAART not shown). Our results predict that X4 strains are more virulent during pediatric infection and are difficult to control exclusively through suppression of blood viral load.

In HIV-1-infected patients, TREC concentrations and naive $\mathrm{T}$ cell numbers were measured to monitor thymic output of RTE after initiation of HAART [2-7]. TREC concentrations in some patients have been observed to recover to normal levels during HAART $[2,6,7]$. A recovery in naive $T$ cell levels was characterized after HAART is initiated in HIV-1-infected patients [3,4]. We compute the number of total $\mathrm{CD} 4^{+}$and $\mathrm{CD} 8^{+} \mathrm{RTE}$ per day in pediatric patients to predict RTE dynamics during HAART. Total $\mathrm{CD}^{+}{ }^{+}$and $\mathrm{CD} 8^{+}$RTE levels per day in healthy individuals increase to their maximum at age 1 and then decrease due to thymic involution (Fig. 3, solid lines). HAART induces a recovery of total RTE levels per day to almost normal during pediatric R5 infection, regardless of thymic drug efficacy (Fig. 3A, dotted lines). However, thymic drug efficacy contributes greatly to RTE levels per day during X4 infection under HAART. With the increase in thymic drug efficacy from 0 to $100 \%$, HAART can reconstitute RTE levels per day during X4 infection (Fig. 3B, dotted lines).

\section{Different thymic drug efficacies in pediatric patients}

Thymic dysfunction was hypothesized in a subgroup of HIV-1-infected children (approximately 15\%) who have faster disease progression and marked early decreases in $\mathrm{CD}^{+}{ }^{+}$and $\mathrm{CD} 8^{+} \mathrm{T}$ cell counts compared with most pediatric patients [22]. We demonstrated through modeling that thymic infection with $\mathrm{X} 4$ strains induces thymic dysfunction, correlating with a faster disease progression in a subgroup of HIV-1-infected children, while thymic infection with R5 strains occurs in most pediatric patients who follow a typical disease progression [21]. To explore optimal strategies for recovery of thymic function, we study antiretroviral drug efficacy in the thymus by simulating the number of $\mathrm{CD}^{+} \mathrm{RTE}$ produced per day during thymic R5 or X4 infection under different treatment regimens. Since most newly generated $\mathrm{T}$ cells are derived from the thymus in young children, tracking changes in $\mathrm{CD} 4^{+}$RTE levels per 

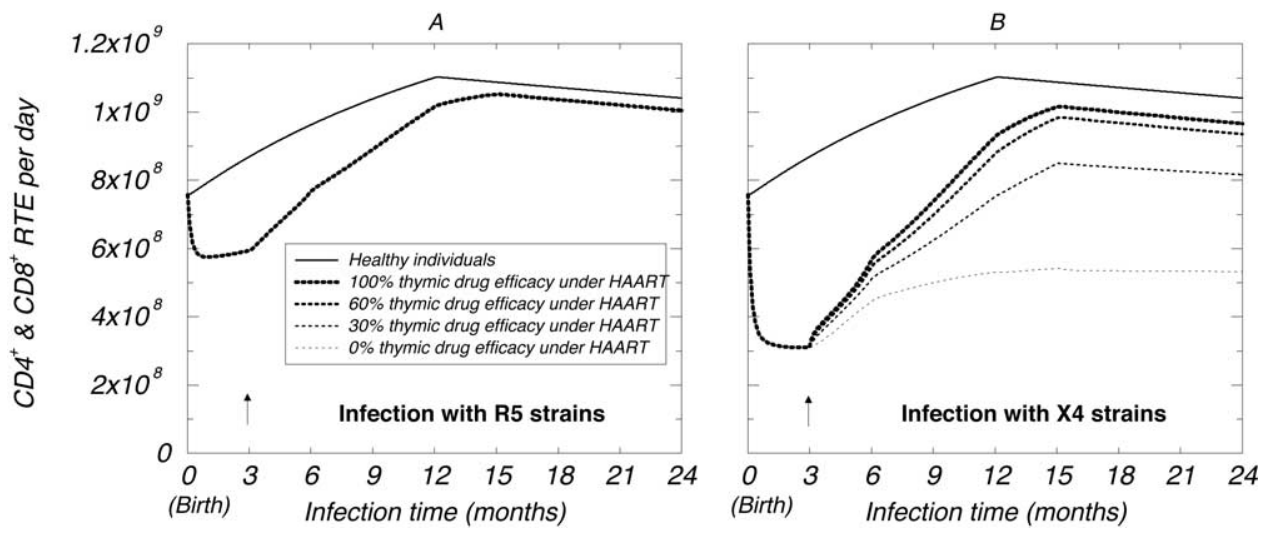

Fig. 3. Virtual pediatric infection: simulations of total $\mathrm{CD} 4^{+}$and $\mathrm{CD} 8^{+} \mathrm{RTE}$ exported per day during HAART. Five scenarios are presented: healthy controls and 100, 60, 30, and 0\% thymic drug efficacy during HAART. HIV-1 infection occurs at birth. The arrow points to the time when HAART is initiated during R5 or X4 infection. A represents R5 infection under HAART with different thymic drug efficacies (note that all dotted lines lie on top of one another). B represents $\mathrm{X} 4$ infection under HAART with different thymic drug efficacies.
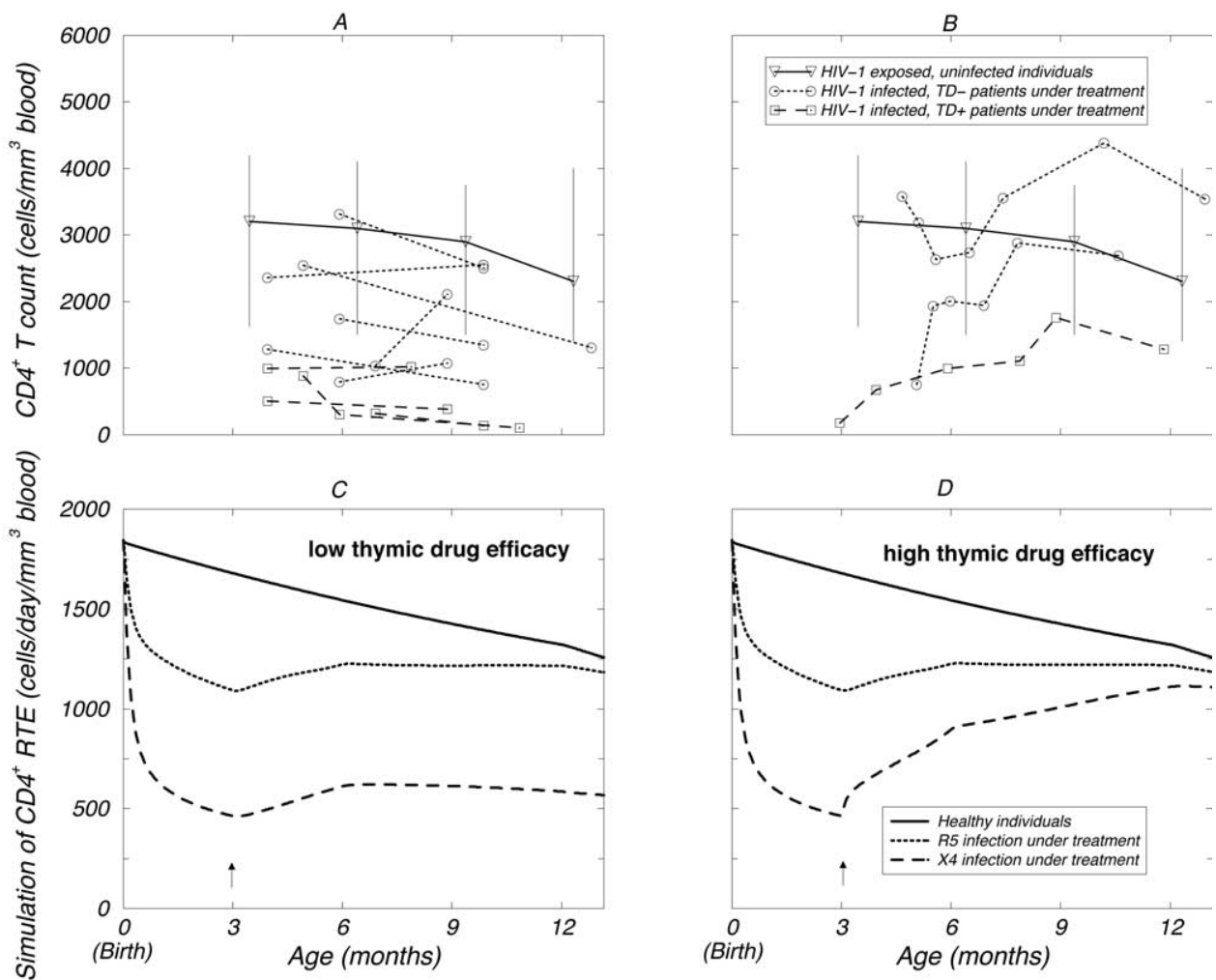

Fig. 4. Simulations of $\mathrm{CD} 4^{+}$RTE exported from the thymus per day predict clinical data on $\mathrm{CD} 4^{+} \mathrm{T}$ cell count in blood for pediatric patients during HIV-1 treatment. Model simulation of HIV-1 infection occurring at birth and treatment initiating at 3 months of age designated by the arrow. A represents CD $4^{+}$ $\mathrm{T}$ cell counts in the blood for four $\mathrm{TD}^{+}$HIV-1-infected children and seven $\mathrm{TD}^{-}$HIV-1-infected children during nucleoside analogue treatment initiating between 5 and 6 months of age (see Table 1). The median and range (from the 10th to the 90th percentile) of CD4 ${ }^{+}$T cell counts in an uninfected cohort of children serve as the control [22]. B represents $\mathrm{CD}^{+} \mathrm{T}$ cell counts in the blood for one $\mathrm{TD}^{+} \mathrm{HIV}-1$-infected child during HAART initiated at 3 months of age and for two TD ${ }^{-}$HIV-1-infected children during HAART initiated at age of 5 months (see Table 1), median and range (from the 10th to the 90th percentile) of $\mathrm{CD}^{+} \mathrm{T}$ cell counts in an uninfected cohort of children as control [22]. C represents three model simulations of CD4 ${ }^{+} \mathrm{RTE}$ per day during no infection, infection with R5, and infection with X4 when treatment starts at 3 months of age with low thymic drug efficacy. The $0 \%$ thymic drug efficacy is plotted as an example of low thymic drug efficacy. D represents three model simulations of $\mathrm{CD}^{+}{ }^{+} \mathrm{RTE}$ per day during no infection, infection with R5, and infection with $\mathrm{X} 4$ when treatment starts at 3 months of age with high thymic drug efficacy. The $100 \%$ thymic drug efficacy is plotted as an example of high thymic drug efficacy. 
day represents, or at least are proportional to, clinical data on $\mathrm{CD}^{+} \mathrm{T}$ cell levels in blood (see [21]).

During the time when HIV-1-induced thymic dysfunction was first described, therapy included only one or two nucleoside analogues of reverse transcriptase inhibitors. In Fig. 4A, solid lines represent the median and range (from the 10th to the 90th percentile) of $\mathrm{CD}^{+} \mathrm{T}$ cell counts in blood for an uninfected cohort of children [22]. Treatment initiation with nucleoside analogues does not induce a $\mathrm{CD}^{+} \mathrm{T}$ cell rebound in $\mathrm{TD}^{+}$HIV-1-infected children (dashed lines) (Table 1: patients 1-4); however, $\mathrm{CD}^{+} \mathrm{T}$ cell counts return to, or close to, normal ranges in $\mathrm{TD}^{-}$children (dotted lines) (Table 1: patients 6-12). We simulate $\mathrm{CD}^{+}{ }^{+} \mathrm{RTE}$ levels per day corresponding to $\mathrm{CD} 4^{+} \mathrm{T}$ cell levels in blood to predict how nucleoside analogues function within the thymus. Comparing Figs. $4 \mathrm{~A}$ and $4 \mathrm{C}$, our model suggests that nucleoside analogues have low thymic drug efficacy (Fig. 4C). Solid lines represent model simulations of $\mathrm{CD} 4^{+}$RTE levels per day in healthy individuals without treatment. Assuming that $\mathrm{TD}^{-}$and $\mathrm{TD}^{+}$patients are infected by $\mathrm{R} 5$ and $\mathrm{X} 4$ strains, respectively, nucleoside treatment retrieves $\mathrm{CD} 4^{+} \mathrm{RTE}$ levels per day in $\mathrm{TD}^{-}$patients (dotted lines), but does not rescue RTE levels per day in $\mathrm{TD}^{+}$patients (dashed lines). This phenomenon might be related to low efficacy of nucleoside analogues acting in the thymus to control $\mathrm{X} 4$ viral replication.

Currently, most HIV-1-infected children are followed from birth and initiated very early on HAART, which now includes at least one protease inhibitor. Therefore, most children within the United States do not experience a severe drop in $\mathrm{CD} 4^{+} \mathrm{T}$ cell counts, and children with thymic dysfunction are rarely seen in the clinic. Shown in Fig. 4B are the median and range (from the 10th to the 90th percentile) of $\mathrm{CD}^{+}{ }^{+} \mathrm{T}$ cells in blood for a cohort of uninfected children (solid lines) [22] and $\mathrm{CD}^{+}{ }^{+} \mathrm{T}$ cell counts for one $\mathrm{TD}^{+}$patient (dashed line) (Table 1: patient 5) and two $\mathrm{TD}^{-}$patients (dotted lines) (Table 1: patients 13-14) who are on HAART. Both $\mathrm{TD}^{+}$and $\mathrm{TD}^{-}$patients demonstrate an increase in $\mathrm{CD} 4^{+} \mathrm{T}$ cell levels very early after initiation of HAART, approaching the normal range of $\mathrm{CD}^{+}{ }^{+} \mathrm{T}$ cells in uninfected individuals. Our model predicts that HAART agents have high thymic drug efficacy (Fig. 4D). As we demonstrated above that nucleoside analogues have low thymic drug efficacy, our results suggest that high thymic efficacy of HAART agents is mainly achieved through protease inhibitors. Another possibility is that the combination of nucleoside analogues and protease inhibitors reaches high efficacy within the thymus. Assuming that $\mathrm{TD}^{-}$and $\mathrm{TD}^{+}$patients are infected by R5 and X4 strains, respectively, our model shows that HAART can induce reconstitution of $\mathrm{CD}^{+}$RTE levels per day for both $\mathrm{TD}^{+}$and $\mathrm{TD}^{-}$patients. This may be related to a high efficacy of protease inhibitors to directly control $\mathrm{X} 4$ viral replication within the thymus.

\section{Impact of HAART on adult thymic function}

To study thymic function recovery in HIV-1-infected adults, we initiate treatment in the third month of HIV-1 infection in a virtual group aged 30. In healthy individuals without HAART, total thymocytes gradually decrease due to normal thymic involution and the SP4/SP8 ratio remains at 2 (Figs. 5A and 5B, solid lines). During HIV-1 infection without thymic drug efficacy, HAART retrieves total thymocyte numbers and the SP4/SP8 ratio returns to almost normal levels for either R5 or X4 infection (Figs. 5A and $5 \mathrm{~B}$, dotted and dashed lines). Similar results for total thymocyte number and SP4/SP8 ratio are also obtained if drugs achieve $100 \%$ efficacy within the thymus (simulation data on HAART not shown).

Total numbers of $\mathrm{CD}^{+}{ }^{+}$and $\mathrm{CD} 8^{+}$RTE per day in healthy individuals aged 30 gradually decrease (Figs. 5C and 5D, solid lines). HAART restores total RTE levels per day for either R5 or X4 infection, which is independent of drug efficacy within the thymus (Figs. 5C and 5D, dotted lines). Our results imply that normal involution of the thymus in adults limits X4 replication, inducing a similar response to treatment as R5 infection. This is in contrast to treatment of X4 infection in children. Consistent with our data, TREC concentrations in some adult virological responders can recover to normal levels [6,7]. Our model also suggests that treatment initiated later during the course of HIV-1 infection (for example, after 1 year of infection), which is most likely for adults, can eventually restore thymic function to the same levels as treatment initiated in the third month of HIV-1 infection (simulation data on HAART not shown).

\section{Discussion}

HAART markedly reduces HIV-1 viral burden in the periphery. Evidence suggests that reconstitution of immune function in HIV-1-infected patients undergoing HAART can occur [1]. The thymus becomes an important target to aid $\mathrm{T}$ cell immunity recovery as it provides newly generated $\mathrm{T}$ cells that respond to both recall and new antigens. Information on recovery of the thymus would yield substantial new insights about regulation of the human immune system during HIV-1 infection.

We performed virtual treatment trials using an existing model of thymic HIV-1 infection in both children and adults [21]. Our results indicate two phases of thymic restoration after treatment. The first phase results directly from decreasing viral influx from the periphery by suppression of blood viral load. Recent studies have suggested that thymic infection with HIV-1 can be controlled by halting viral influx from blood $[2,6]$. The second phase is induced by recovery 

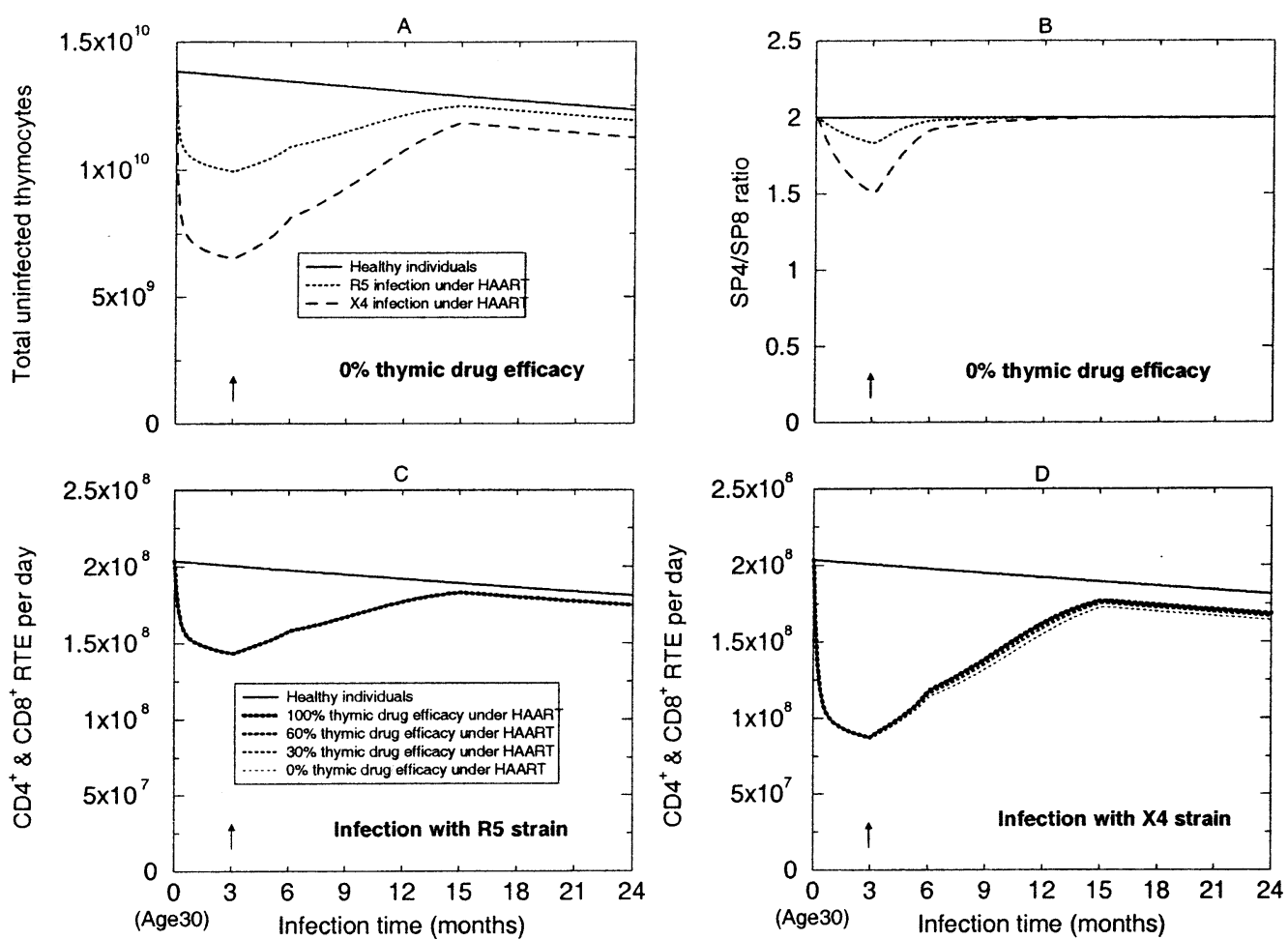

Fig. 5. Virtual adult infection: simulations of thymocyte dynamics and total $\mathrm{CD} 4^{+}$and $\mathrm{CD} 8^{+} \mathrm{RTE}$ exported per day during HAART. HIV-1 infection occurs at age of 30. The arrow points to the time when HAART is initiated during R5 or X4 infection. A represents total uninfected thymocytes if HAART has $0 \%$ thymic efficacy. B represents SP4/SP8 ratio if HAART has $0 \%$ thymic efficacy. C represents total CD4 ${ }^{+}$and $\mathrm{CD} 8^{+} \mathrm{RTE}$ during R5 infection with different thymic drug efficacies (note that all dotted lines lie on top of one another). D represents total $\mathrm{CD} 4^{+}$and $\mathrm{CD} 8^{+} \mathrm{RTE}$ during X4 infection with different thymic drug efficacies.

of inherent thymic function, including limiting thymic inflammation [31], and normalizing stromal cell function and the cytokine network. Bone marrow may also benefit from suppressing peripheral viral loads, providing more progenitor cells to the thymus [26,27]. We simulated treatment only for virological responders in order to explore the role of effective therapy on recovery of thymic function. For virological nonresponders, their TREC concentrations do not increase despite therapy $[2,6]$, which is consistent with our results that thymic infection cannot be controlled without significantly reducing viral influx into the thymus from blood.

Few data are available regarding thymic penetration and concomitant changes of HIV-1 viral loads during treatment with antiretroviral agents. In the absence of adequate thymic penetration by drugs in a potent antiretroviral therapy regimen, the thymus could become a site in which ongoing viral replication may occur. Our model suggests that drug efficacy within the thymus may play an important role in the reconstitution of thymic function. X4 strains are highly virulent and can replicate to high levels within the thymus during pediatric infection [21]. Our model demonstrates that thymic drug efficacy contributes greatly to the recovery of RTE levels for pediatric X4 infection. High thymic drug efficacy inhibits X4 strain replication within the thymus, benefiting thymic function recovery. On the contrary, pediatric R5 infection can be controlled through suppression of viral influx from the blood alone. Therefore, thymic drug efficacy does not affect thymic function recovery during pediatric R5 infection. The thymus undergoes involution during aging, with a decreased number of target thymocytes in adults. Although thymic X4 infection causes more serious effects than R5 infection in adults, intrathymic X4 viral load in adults is not comparable to pediatric X4 infection, due to a more limited target cell number. Therefore, both adult R5 and X4 infection can be controlled by suppression of viral influx from the blood alone.

We simulate $\mathrm{CD}^{+}{ }^{+} \mathrm{RTE}$ levels exported from the thymus per day as a comparison of clinical data on $\mathrm{CD} 4^{+}$ cell counts in the blood for pediatric patients under treatment to predict how HAART agents function within the thymus. Our results indicate that reverse transcriptase inhibitors do not sufficiently restore thymic function during $\mathrm{X} 4$ infection whereas protease inhibitors do. This implies that protease inhibitors may be able to penetrate the thymus and control X4 infection, while reverse transcriptase inhibitors may not. Another possibility is that both protease and reverse transcriptase inhibitors penetrate the thymus but protease inhibitors have higher efficacy than reverse transcriptase inhibitors. One study 
suggests that antiviral nucleosides appear to have limited entry into the brain when given systemically, which may hinder therapy of viral brain diseases, while some protease inhibitors may enter the brain more readily [32]. Such studies, to our knowledge, have not been performed with regard to the thymus. Therefore, determining the physiologic mechanisms that might limit drug access to the thymus and devising methods to ensure delivery and maintenance of drug concentrations in the tissue might be keys to achieving thymic restoration.

Taken together, our model demonstrates that with adequate suppression of viral replication in both thymus and blood during treatment, recovery of thymic function is possible and should aid in overall naive $\mathrm{T}$ cell reconstitution. Results from SCID-hu mice have shown that, following HAART treatment, newly reconstituted thymocytes are phenotypically and functionally normal $[28,29]$. Later in the course of HAART, the proliferative response of $\mathrm{T}$ cells to antigens can recover and TCR repertoires become normalized $[11,33]$. Thus, restoration of thymic function should be a goal of HIV-1 treatment. Sustained increases in thymic export may eventually restore immune function.

\section{Appendix}

Equations and parameter values for thymic infection model have been illustrated before [21]. We modified equations and parameters in this model to simulate HAART effects on thymic function.

The dynamics of five uninfected thymocyte subsets during R5 or X4 infection under HAART are described as follows, where $T$ represents TN cells, $I$ represents ITTP cells, $D$ represents DP cells, $S_{4}$ represents SP4 cells, and $S_{8}$ represents SP8 cells. Treatment effects are denoted by boldface letters.

$$
\begin{aligned}
\frac{d T}{d t}= & s(t)-\frac{\frac{s(t)}{2}\left(R_{5}+X_{4}\right)}{\mathbf{c}_{\mathbf{1}}(\mathbf{t})+\left(R_{5}+X_{4}\right)}+r_{1}\left(1-\frac{z(t)}{k(t)-\frac{k(t) R_{5}}{4\left(\mathbf{c}_{2}(\mathbf{t})+R_{5}\right)}-\frac{k(t) X_{4}}{2\left(\mathbf{c}_{2}(t)+X_{4}\right)}}\right) T \\
& -f_{1} T-\left(d_{1}+\frac{m_{1} R_{5}}{\mathbf{c}_{3}(\mathbf{t})+R_{5}}+\frac{n_{1} X_{4}}{\mathbf{c}_{3}(\mathbf{t})+X_{4}}\right) T, \\
\frac{d I}{d t}= & f_{1} T+r_{2}\left(1-\frac{k(t)}{k(t)-\frac{k(t) R_{5}}{4\left(\mathbf{c}_{2}(\mathbf{t})+R_{5}\right)}-\frac{k(t) X_{4}}{2\left(\mathbf{c}_{2}(\mathbf{t})+X_{4}\right)}}\right) I \\
& -f_{2} I-\left(d_{2}+\frac{m_{2} R_{5}}{\mathbf{c}_{3}(\mathbf{t})+R_{5}}+\frac{n_{2} X_{4}}{\mathbf{c}_{3}(\mathbf{t})+X_{4}}\right) I-\mathbf{w}(\mathbf{t}) \beta_{1}^{X} X_{4} I,
\end{aligned}
$$

$$
\begin{aligned}
\frac{d D}{d t}= & f_{2} I+r_{3}\left(1-\frac{z(t)}{k(t)-\frac{k(t) R_{5}}{4\left(\mathbf{c}_{2}(\mathbf{t})+R_{5}\right)}-\frac{k(t) X_{4}}{2\left(\mathbf{c}_{2}(\mathbf{t})+X_{4}\right)}}\right) D-f_{3} D-f_{4} D-\left(d_{3}+\frac{m_{3} R_{5}}{\mathbf{c}_{3}(\mathbf{t})+R_{5}}+\frac{n_{3} X_{4}}{\mathbf{c}_{3}(\mathbf{t})+X_{4}}\right) D \\
& -\mathbf{w}(\mathbf{t}) \beta_{1}^{R} R_{5} D-\mathbf{w}(\mathbf{t}) \beta_{2}^{X} X_{4} D,
\end{aligned}
$$

$$
\begin{aligned}
\frac{d S_{4}}{d t}= & f_{3} D+r_{4}\left(1-\frac{z(t)}{k(t)-\frac{k(t) R_{5}}{4\left(\mathbf{c}_{2}(\mathbf{t})+R_{5}\right)}-\frac{k(t) X_{4}}{2\left(\mathbf{c}_{2}(\mathbf{t})+X_{4}\right)}}\right) S_{4}-e_{1} S_{4}-\left(d_{4}+\frac{m_{4} R_{5}}{\mathbf{c}_{3}(\mathbf{t})+R_{5}}+\frac{n_{4} X_{4}}{\mathbf{c}_{3}(\mathbf{t})+X_{4}}\right) S_{4} \\
& -\mathbf{w}(\mathbf{t}) \beta_{2}^{R} R_{5} S_{4}-\mathbf{w}(\mathbf{t}) \beta_{3}^{X} X_{4} S_{4},
\end{aligned}
$$

$$
\frac{d S_{8}}{d t}=f_{4} D+r_{5}\left(1-\frac{z(t)}{k(t)-\frac{k(t) R_{5}}{4\left(\mathbf{c}_{2}(\mathbf{t})+R_{5}\right)}-\frac{k(t) X_{4}}{2\left(\mathbf{c}_{2}(\mathbf{t})+X_{4}\right)}}\right) S_{8}-e_{2} S_{8}-\left(d_{5}+\frac{m_{5} R_{5}}{\mathbf{c}_{3}(\mathbf{t})+R_{5}}+\frac{n_{5} X_{4}}{\mathbf{c}_{3}(\mathbf{t})+X_{4}}\right) S_{8}
$$


The rates of change of R5-infected thymocytes (with the superscript $R$ indicating infected cell class) and $\mathrm{R} 5$ virus are illustrated below, where boldface letters represent effects of HAART. The effect of treatment on X4 infection is written similarly to that during R5 infection (equations not shown).

$$
\begin{aligned}
& \frac{d D^{R}}{d t}=\mathbf{w}(\mathbf{t}) \beta_{1}^{R} R_{5} D-f_{1}^{R} D^{R}-f_{2}^{R} D^{R}-d_{1}^{R} D^{R}, \\
& \frac{d S_{4}^{R}}{d t}=f_{1}^{R} D^{R}+\mathbf{w}(\mathbf{t}) \beta_{2}^{R} R_{5} S_{4}-e_{1}^{R} S_{4}^{R}-d_{2}^{R} S_{4}^{R}, \\
& \frac{d S_{8}^{R}}{d t}=f_{2}^{R} D^{R}-e_{2}^{R} S_{8}^{R}-d_{3}^{R} S_{8}^{R} . \\
& \frac{d R_{5}}{d t}=s^{R}(t)+\mathbf{w}(\mathbf{t}) p_{1}^{R} d_{1}^{R} D^{R}+\mathbf{w}(\mathbf{t}) p_{2}^{R} d_{2}^{R} S_{4}^{R} \\
& \quad+\mathbf{w}(\mathbf{t}) p_{3}^{R} d_{3}^{R} S_{8}^{R}-\varepsilon^{R} R_{5}-\delta^{R} R_{5},
\end{aligned}
$$

where

$$
s^{R}(t)=\frac{\mathbf{v}(\mathbf{t}) s_{0}^{R} t}{c_{4}+t}
$$

is the rate of viral influx from blood.

The initiation of thymic infection with HIV-1 marks time 0 . HAART is simulated 3 months after infection in both pediatric and adult models. The function $\mathbf{v}(\mathbf{t})$ simulates the reduction of blood viral load during HAART [3,8]. We suppress the rate of viral influx from blood into the thymus to the same levels for pediatric and adult patients.

$$
\begin{gathered}
\mathbf{v}(\mathbf{t}) \\
=\left\{\begin{array}{lc}
1 & \\
10^{-t / 3 \operatorname{mos}+1} & \text { (children) } 10^{-0.7 t / 3 \mathrm{mos}+0.7} \text { (adults) } \\
0.1 & \text { (children) } 0.2 \text { (adults) } \\
\text { for } 0 \leq t<3 \text { mos } \\
\text { for } 3 \operatorname{mos} \leq t<6 \text { mos } \\
\text { for } 6 \operatorname{mos} \leq t
\end{array}\right.
\end{gathered}
$$

The function $\mathbf{c}_{\mathbf{1}}(\mathbf{t})$ represents the effect of increased numbers of hemopoietic progenitor cells from bone marrow into the thymus after HAART is initiated [26,27]. The observed augmented volume of thymic tissue after HAART is represented by the function $\mathbf{c}_{\mathbf{2}}(\mathbf{t})[5,8,9]$. Restoration in thymic function during HAART also decreases the HIV-1-induced death of uninfected thymocytes, illustrated by the function $\mathbf{c}_{\mathbf{3}}(\mathbf{t})[28,29]$.

$$
\begin{aligned}
& \mathbf{c}_{1}(\mathbf{t}) \\
& =\left\{\begin{array}{cc}
10^{6} & \text { for } 0 \leq t<3 \mathrm{mos} \\
10^{2 / 12 \operatorname{mos} \times(t-3 \operatorname{mos})+6} & \text { for } 3 \operatorname{mos} \leq t<15 \operatorname{mos} \\
10^{8} & \text { for } 15 \operatorname{mos} \leq t
\end{array}\right.
\end{aligned}
$$

$$
\begin{gathered}
\mathbf{c}_{2}(\mathbf{t}) \\
=\left\{\begin{array}{cc}
10^{5} & \text { for } 0 \leq t<3 \text { mos } \\
10^{2 / 12 \operatorname{mos} \times(t-3 \operatorname{mos})+5} & \text { for } 3 \operatorname{mos} \leq t<15 \operatorname{mos} \\
10^{7} & \text { for } 15 \operatorname{mos} \leq t
\end{array}\right.
\end{gathered}
$$

$$
\begin{aligned}
& \mathbf{c}_{3}(\mathbf{t}) \\
& \quad=\left\{\begin{array}{cc}
10^{7} & \text { for } 0 \leq t<3 \mathrm{mos} \\
10^{2 / 12 \operatorname{mos} \times(t-3 \operatorname{mos})+7} & \text { for } 3 \operatorname{mos} \leq t<15 \operatorname{mos} \\
10^{9} & \text { for } 15 \operatorname{mos} \leq t
\end{array}\right.
\end{aligned}
$$

Drug efficacy within the thymus is represented by multiplying viral infection term and viral production term by the function $\mathbf{w}(\mathbf{t})$. If drug efficacy is $0 \%, \mathbf{w}(\mathbf{t})$ equals 1 at any time. The $100 \%$ drug efficacy is described by the following function; different percentages for drug efficacy can be calculated and easily implemented.

$$
\mathbf{w}(\mathbf{t})= \begin{cases}1.0 & \text { for } 0 \leq t<3 \mathrm{mos} \\ 0.46 & \text { for } 3 \operatorname{mos} \leq t\end{cases}
$$

\section{Acknowledgments}

This work was supported by National Institutes of Health Grant HL62119 and The Whitaker Foundation to DEK and a Rackham Predoctoral Fellowship and Elizabeth Glaser Pediatric AIDS Foundation Student Intern Award to PY. We thank Dr. Annemarie van Rossum for kindly providing us with $\mathrm{CD} 4 / \mathrm{CD} 8 \mathrm{~T}$ cell counts and treatment information for two $\mathrm{TD}^{-}$patients treated with HAART (Table 1: patients 13 and 14).

\section{References}

[1] G.D. Sempowski, B.F. Haynes, Immune reconstitution in patients with HIV infection, Annu. Rev. Med. 53 (2002) 269-284.

[2] D.C. Douek, R.A. Koup, R.D. McFarland, J.L. Sullivan, K. Luzuriaga, Effect of HIV on thymic function before and after antiretroviral therapy in children, J. Infect. Dis. 181 (2000) 1479-1482.

[3] D.M. Gibb, A. Newberry, N. Klein, A. de Rossi, I. Grosch-Woerner, A. Babiker, Immune repopulation after HAART in previously untreated HIV-1-infected children. Paediatric European Network for Treatment of AIDS (PENTA) Steering Committee [letter], Lancet 355 (2000) 1331-1332.

[4] J.M. Franco, J.A. Leon-Leal, M. Leal, A. Cano-Rodriguez, J.A. Pineda, J. Macias, A. Rubio, C. Rey, B. Sanchez, E. Lissen, CD4 ${ }^{+}$ and $\mathrm{CD}^{+} \mathrm{T}$ lymphocyte regeneration after anti-retroviral therapy in HIV-1-infected children and adult patients, Clin. Exp. Immunol. 119 (2000) 493-498.

[5] J.M. Franco, A. Rubio, M. Martinez-Moya, M. Leal, E. Merchante, A. Sanchez-Quijano, E. Lissen, T-cell repopulation and thymic volume in HIV-1-infected adult patients after highly active antiretroviral therapy, Blood 99 (2002) 3702-3706.

[6] D.C. Douek, R.D. McFarland, P.H. Keiser, E.A. Gage, J.M. Massey, B.F. Haynes, M.A. Polis, A.T. Haase, M.B. Feinberg, J.L. Sullivan, 
B.D. Jamieson, J.A. Zack, L.J. Picker, R.A. Koup, Changes in thymic function with age and during the treatment of HIV infection [see comments], Nature 396 (1998) 690-695.

[7] L. Zhang, S.R. Lewin, M. Markowitz, H.H. Lin, E. Skulsky, R. Karanicolas, Y. He, X. Jin, S. Tuttleton, M. Vesanen, H. Spiegel, R. Kost, J. van Lunzen, H.J. Stellbrink, S. Wolinsky, W. Borkowsky, P. Palumbo, L.G. Kostrikis, D.D. Ho, Measuring recent thymic emigrants in blood of normal and HIV-1-infected individuals before and after effective therapy, J. Exp. Med. 190 (1999) 725-732.

[8] K.Y. Smith, H. Valdez, A. Landay, J. Spritzler, H.A. Kessler, E. Connick, D. Kuritzkes, B. Gross, I. Francis, J.M. McCune, M.M. Lederman, Thymic size and lymphocyte restoration in patients with human immunodeficiency virus infection after 48 weeks of zidovudine, lamivudine, and ritonavir therapy, J. Infect. Dis. 181 (2000) 141-147.

[9] A. Vigano, S. Vella, M. Saresella, A. Vanzulli, D. Bricalli, S. Di Fabio, P. Ferrante, M. Andreotti, M. Pirillo, L.G. Dally, M. Clerici, N. Principi, Early immune reconstitution after potent antiretroviral therapy in HIV-infected children correlates with the increase in thymus volume, AIDS 14 (2000) 251-261.

[10] M.L. Markert, A.P. Alvarez-McLeod, G.D. Sempowski, L.P. Hale, J.M. Horvatinovich, K.J. Weinhold, J.A. Bartlett, T.A. D'Amico, B.F. Haynes, Thymopoiesis in HIV-infected adults after highly active antiretroviral therapy, AIDS Res. Hum. Retroviruses 17 (2001) 16351643.

[11] L. Kolte, A.M. Dreves, A.K. Ersboll, C. Strandberg, D.L. Jeppesen, J.O. Nielsen, L.P. Ryder, S.D. Nielsen, Association between larger thymic size and higher thymic output in human immunodeficiency virus-infected patients receiving highly active antiretroviral therapy, J. Infect. Dis. 185 (2002) 1578-1585.

[12] L.K. Schrager, M.P. D'Souza, Cellular and anatomical reservoirs of HIV-1 in patients receiving potent antiretroviral combination therapy, J. Am. Med. Assoc. 280 (1998) 67-71.

[13] H. Zhang, G. Dornadula, M. Beumont, L. Livornese Jr., B. Van Uitert, K. Henning, R.J. Pomerantz, Human immunodeficiency virus type 1 in the semen of men receiving highly active antiretroviral therapy, N. Engl. J. Med. 339 (1998) 1803-1809.

[14] A. Kitami, T. Suzuki, Y. Kamio, S. Suzuki, Chemotherapy of thymic carcinoma: Analysis of seven cases and review of the literature, Jpn. J. Clin. Oncol. 31 (2001) 601-604.

[15] N.A. Foudraine, R.M. Hoetelmans, J.M. Lange, F. de Wolf, B.H. van Benthem, J.J. Maas, I.P. Keet, P. Portegies, Cerebrospinal-fluid HIV-1 RNA and drug concentrations after treatment with lamivudine plus zidovudine or stavudine, Lancet 351 (1998) 1547-1551.

[16] S.J. Haworth, B. Christofalo, R.D. Anderson, L.M. Dunkle, A singledose study to assess the penetration of stavudine into human cerebrospinal fluid in adults, J. Acquir. Immune. Defic. Syndr. Hum. Retrovirol. 17 (1998) 235-238.

[17] L.L. Lewis, D. Venzon, J. Church, M. Farley, S. Wheeler, A. Keller, M. Rubin, G. Yuen, B. Mueller, M. Sloas, L. Wood, F. Balis, G.M. Shearer, P. Brouwers, J. Goldsmith, P.A. Pizzo, Lamivudine in children with human immunodeficiency virus infection: A phase I/II study. The National Cancer Institute Pediatric Branch-Human Immunodeficiency Virus Working Group, J. Infect. Dis. 174 (1996) 16-25.

[18] R.M. van Praag, G.J. Weverling, P. Portegies, S. Jurriaans, X.J. Zhou, M.L. Turner-Foisy, J.P. Sommadossi, D.M. Burger, J.M. Lange, R.M. Hoetelmans, J.M. Prins, Enhanced penetration of indinavir in cerebrospinal fluid and semen after the addition of low-dose ritonavir, AIDS 14 (2000) 1187-1194.

[19] S. Kravcik, K. Gallicano, V. Roth, S. Cassol, N. Hawley-Foss, A. Badley, D.W. Cameron, Cerebrospinal fluid HIV RNA and drug levels with combination ritonavir and saquinavir, J. Acquir. Immune. Defic. Syndr. 21 (1999) 371-375.

[20] P. Ye, D.E. Kirschner, Reevaluation of T cell receptor excision circles as a measure of human recent thymic emigrants, J. Immunol. 168 (2002) 4968-4979.

[21] P. Ye, A.P. Kourtis, D.E. Kirschner, The effects of different HIV-1 strains on human thymic function, AIDS Res. Hum. Retroviruses 18 (2002) 1239-1251.

[22] A.P. Kourtis, C. Ibegbu, A.J. Nahmias, F.K. Lee, W.S. Clark, M.K. Sawyer, S. Nesheim, Early progression of disease in HIV-infected infants with thymus dysfunction [published erratum appears in N. Engl. J. Med. 336(8) (1997) 595], N. Engl. J. Med. 335 (1996) $1431-1436$.

[23] A.M. van Rossum, S.P. Geelen, N.G. Hartwig, T.F. Wolfs, C.M. Weemaes, H.J. Scherpbier, E.G. van Lochem, W.C. Hop, M. Schutten, A.D. Osterhaus, D.M. Burger, R. de Groot, Results of 2 years of treatment with protease-inhibitor-containing antiretroviral therapy in Dutch children infected with human immunodeficiency virus type 1, Clin. Infect. Dis. 34 (2002) 1008-1016.

[24] E.A. Berger, R.W. Doms, E.M. Fenyo, B.T. Korber, D.R. Littman, J.P. Moore, Q.J. Sattentau, H. Schuitemaker, J. Sodroski, R.A. Weiss, A new classification for HIV-1 [letter], Nature 391 (1998) 240.

[25] M.L. Markert, C.B. Hicks, J.A. Bartlett, J.L. Harmon, L.P. Hale, M.L. Greenberg, G. Ferrari, J. Ottinger, A. Boeck, A.L. Kloster, T.M. McLaughlin, K.B. Bleich, R.M. Ungerleider, H.K. Lyerly, W.E. Wilkinson, F.S. Rousseau, M.E. Heath-Chiozzi, J.M. Leonard, A.T. Haase, G.M. Shaw, R.P. Bucy, D.C. Douek, R.A. Koup, B.F. Haynes, D.P. Bolognesi, K.J. Weinhold, Effect of highly active antiretroviral therapy and thymic transplantation on immunoreconstitution in HIV infection, AIDS Res. Hum. Retroviruses 16 (2000) 403-413.

[26] T. Bohler, J. Walcher, G. Holzl-Wenig, M. Geiss, B. Buchholz, R. Linde, K.M. Debatin, Early effects of antiretroviral combination therapy on activation, apoptosis and regeneration of $\mathrm{T}$ cells in HIV1-infected children and adolescents, AIDS 13 (1999) 779-789.

[27] A. Isgro, I. Mezzaroma, A. Aiuti, L. De Vita, F. Franchi, F. Pandolfi, C. Alario, F. Ficara, E. Riva, G. Antonelli, F. Aiuti, Recovery of hematopoietic activity in bone marrow from human immunodeficiency virus type-1-infected patients during highly active antiretroviral therapy [In Process Citation], AIDS Res. Hum. Retroviruses 16 (2000) 1471-1479.

[28] S.G. Kitchen, S. Killian, J.V. Giorgi, J.A. Zack, Functional reconstitution of thymopoiesis after human immunodeficiency virus infection, J. Virol. 74 (2000) 2943-2948.

[29] E.S. Withers-Ward, R.G. Amado, P.S. Koka, B.D. Jamieson, A.H. Kaplan, I.S. Chen, J.A. Zack, Transient renewal of thymopoiesis in HIV-infected human thymic implants following antiviral therapy, Nat. Med. 3 (1997) 1102-1109.

[30] A.P. Kourtis, M. Bulterys, S.R. Nesheim, F.K. Lee, Understanding the timing of HIV transmission from mother to infant, Am. Med. Assoc. 285 (2001) 709-712.

[31] K.A. Hayes, A.J. Phipps, S. Francke, L.E. Mathes, Antiviral therapy reduces viral burden but does not prevent thymic involution in young cats infected with feline immunodeficiency virus, Antimicrob. Agents. Chemother. 44 (2000) 2399-2405.

[32] D.R. Groothuis, R.M. Levy, The entry of antiviral and antiretroviral drugs into the central nervous system, J. Neurovirol. 3 (1997) 387400 .

[33] G. Gorochov, A.U. Neumann, A. Kereveur, C. Parizot, T. Li, C. Katlama, M. Karmochkine, G. Raguin, B. Autran, P. Debre, Perturbation of $\mathrm{CD} 4+$ and $\mathrm{CD} 8+\mathrm{T}$-cell repertoires during progression to AIDS and regulation of the CD4+ repertoire during antiviral therapy [see comments], Nat. Med. 4 (1998) 215-221. 